\title{
Development of a High-Precision Calorimeter for Measuring Power Loss in Electrical Machines
}

\author{
Wenping Cao, Member, IEEE, Keith J. Bradley, Associate Member, IEEE, and Azzeddine Ferrah, Member, IEEE
}

\begin{abstract}
This paper is concerned with the development of a high-precision $30-\mathrm{kW}(40-\mathrm{hp})$ calorimeter and is specifically focused on how experimental errors resulting from calorimeter design and operating procedures are eliminated or mitigated. A complete calibration for the calorimetric system using a dc heater is conducted, and two induction motors rated at 5.5 and $30 \mathrm{~kW}$ (7 and $40 \mathrm{hp}$, respectively) are carefully tested both within and outside of the calorimeter. Loss segregation is in accordance with the IEEE 112 method B. Experimental results for the comparison of calorimetric and input-output methods clearly confirm the effectiveness of the calorimeter in terms of accurate power loss measurement. The accuracy of the calorimeter is approximately $5.6 \mathrm{~W}$ in the measurement of power loss of up to $4.5 \mathrm{~kW}$ with a resolution of $0.1 \mathrm{~W}$.
\end{abstract}

Index Terms-Calorimetry, heat run test, heat transfer, induction motor, loss measurement, power loss.

\section{INTRODUCTION}

$\mathbf{T}$ HE DRIVE for energy efficiency has spurred a growing number of studies on the efficiency improvement of machine drive systems. Advances have been made in theoretical analysis [1], [2] and numerical simulation [3], [4], but experimental verification has proved to be challenging.

The conventional input-output method [5] for determining losses and efficiency is effective, but the measurement of total loss becomes increasingly difficult as machine efficiency or rating increases. The back-to-back method [6] requires two identical machines being mechanically coupled together and forming as a generator-motor set, which may not readily be available. As a result, the need for high-precision techniques of measuring the machine losses is long standing.

In principle, calorimetry is geared toward these requirements. This technique provides a direct measurement of the total loss in electrical machines, removing the necessity of subtracting two similar magnitude input and output power losses. It suffers neither from instrumentation phase shift nor time delay errors [7]. Consequently, it is suitable for measuring electrical

Manuscript received August 13, 2007; revised December 12, 2007. First published September 26, 2008; current version published February 9, 2009. This work was supported in part by U.K. EPSRC under Grant GR/L05051 and in part by Brook Hansen and Eurotherm Drives Ltd. The Associate Editor coordinating the review process for this paper was Dr. V. R. Singh.

W. Cao is with the School of Science and Technology, University of Teesside, TS1 3BA, Middlesbrough, U.K. (e-mail: w.cao@tees.ac.uk).

K. J. Bradley is with the School of Electrical and Electronic Engineering, University of Nottingham, NG7 2RD Nottingham, U.K.

A. Ferrah is with the Faculty of Engineering, Sohar University, Sohar 311, Oman.

Color versions of one or more of the figures in this paper are available online at http://ieeexplore.ieee.org.

Digital Object Identifier 10.1109/TIM.2008.2005083 machines with any efficiency and power rating under any excitation and supply conditions. Due to these inherent features, calorimetry can potentially achieve a very high level of measurement accuracy and is thus gaining in popularity in testing electrical machines and power electronic devices [8]-[19].

However, the calorimetric approach is not without experimental problems. Its major difficulties are found in the measurement of fluid properties [9], prevention of heat leakage [18], and maintenance of repeatable testing conditions [15]. In this paper, the development of a $30-\mathrm{kW}$ calorimeter is described, and these drawbacks are tackled to obtain reliable results over a relatively long operating time.

\section{PRINCIPLE OF CALORIMETER}

The underlying principle of calorimetry is to measure the effect of losses in a stable heat source (e.g., an electrical machine). This is achieved by placing the test object in an enclosed thermally insulated container (i.e., calorimeter) and arranging a cooling fluid to pass through the calorimeter to exhaust the heat generated by the test object. This force-flowed coolant fluid can be either gas or liquid.

When thermal equilibrium is attained, the heat loss extracted from the enclosure is exactly balanced by the power loss released by the test object. This power loss in steady state can be expressed by

$$
P_{\text {loss }}=\rho \times v \times\left(C p_{\text {out }} \times T_{\text {out }}-C p_{\text {in }} \times T_{\text {in }}\right)
$$

where $P_{\text {loss }}$ is the power loss (in watts), $\rho$ is the coolant density (in kilograms per cubic meter), $v$ is the volumetric flow rate (in cubic meters per second), $C p_{\text {in }}$ and $C p_{\text {out }}$ are the specific heats at the entry and exit (in joules per kilogram degree Celsius), and $T_{\text {in }}$ and $T_{\text {out }}$ are the temperatures at the entry and exit (in degrees Celsius).

\section{MEASUREMENT ERROR AND ANALYSES}

Previously, a balanced-type calorimeter was developed by the authors and described in [14]. This calorimeter was capable of measuring power loss of up to $3 \mathrm{~kW}$ with an overall accuracy of approximately $0.5 \%$. Nonetheless, the experimental difficulties encountered were associated with varying fluid properties, heat leakage, and repeatability of the calorimeter. In addition, the length of time that the tests took was considerable since the motor test was followed by a heater run, with each taking at least $4 \mathrm{~h}$ for a load test point. It is very likely that atmospheric conditions fluctuate over this period of time, giving rise to measurement error between the two consecutive tests. This is 
an inherent flaw in the balanced calorimeter, which assumes that the two conditions remain unchanged [9], [14].

The lessons for developing the $30-\mathrm{kW}$ calorimeter have been learned, and these difficulties have carefully been dealt with in the improved design.

\section{A. Measurement of Fluid Properties}

Both calorimeters use air as the coolant because of its convenience and low cost. There is apparently no need for a heat exchanger inside the calorimeter to boost heat transfer, as in a liquid-cooled calorimeter. In the event of fluid leakage, air causes neither environmental hazards nor damage to the laboratory equipment. Using a conditioning system, air can readily be cooled down to a controlled level prior to its supply to the calorimeter. This way, the machine is not operated at excessively high temperatures, as is the case in some calorimeters [16].

To reduce the duration of calorimetric tests, the new design is of direct-type calorimeter [20]. As such a consequence, an accurate determination of fluid properties becomes vital to power calculation. However, this is far from easy to achieve, particularly in the case of using gas (air) as the coolant fluid. In practice, most flow-measuring devices for air measure volume flow rather than mass flow. The density of air changes with temperature and pressure. Atmospheric air also has a varying water vapor content that significantly impacts the specific heat of the mixture. Without a doubt, the use of high-precision instruments can reduce the measurement errors in humidity, pressure, and flow rate to a satisfactory level.

Clearly, the balanced calorimeter or the series calorimeter [15] can remove the need for measuring fluid properties and associated measurement errors. They need to employ a resistive heater to replicate the load test and to operate along with the machine in the sequence of time (balanced) or space (series). Again, there is no guarantee that consecutive tests would be conducted under exactly the same conditions over a relatively long period of time.

\section{B. Temperature Measurement}

However, it is always a problem to measure the mean air temperature with sufficient precision. Ideally, the temperature of the fluid measured at the inlet and outlet ports should be single valued. In the real world, there would be temperature gradients present across the inlet and outlet ducts as well as mass flow and velocity, as shown in Fig. 1. In a steady fully developed forced-ventilated flow, the air temperature distribution across a circular duct exhibits a parabolic shape. Previous studies have shown that the temperature gradient between the duct center and the circumference could be up to $2{ }^{\circ} \mathrm{C}$ in a $150-\mathrm{mm}$ diameter duct [14]. It is obvious that using a single temperature sensor to measure the bulk temperature will unavoidably lead to measurement uncertainty that can easily exceed the accuracy required. This error is often overlooked. In practice, there are two approaches available for minimizing the error. One is adopting multiple temperature sensors in a grid to find a mean temperature [15], and the other is using a
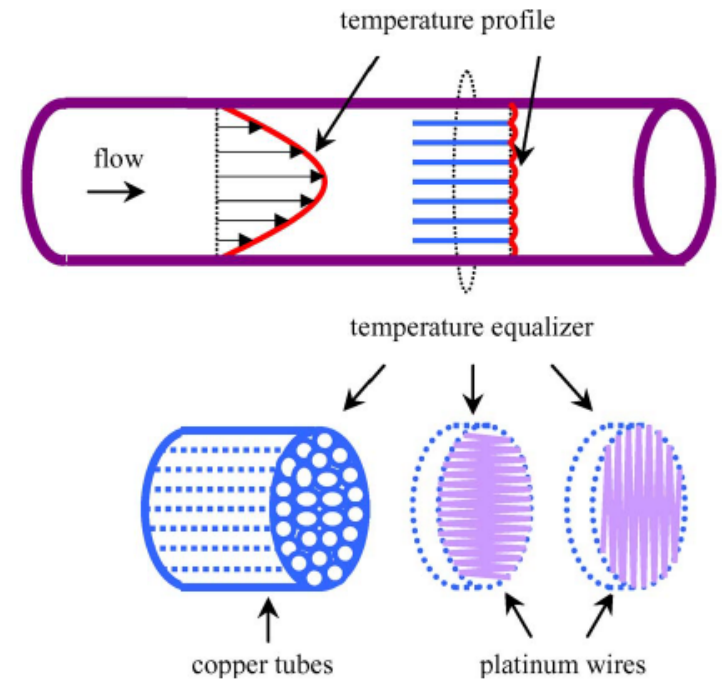

Fig. 1. Temperature equalizer in a force-ventilated duct.

temperature equalizer to average the fluid temperature at the temperature measurement point [21]. The latter is used in this design and is illustrated in detail in Fig. 1.

The temperature equalizer used in this paper comprises an array of 25-mm diameter cooper tubes welded together to form a 200-mm diameter honeycomb. This is then connected to a single centrally located PT 100 temperature sensor. The purpose of this equalizer is twofold. First, it divides the main air flow into many subflows so that the difference in temperature (and flow rate) across the cross section of the duct is considerably reduced. Second, by employing high-conductivity copper tubes and platinum wires, the temperature distribution is equalized.

It is only after the measurement errors in the bulk air temperatures at the inlet and outlet ducts have been significantly reduced that it becomes possible for the coolant temperatures to be controlled to $0.01{ }^{\circ} \mathrm{C}$ of their desired values by both sets of heaters.

\section{Heat Flux Leakage Paths}

Three modes of heat transfer, i.e., convection, conduction, and radiation, are involved in the thermal-dynamic performance of a calorimeter, as shown in Fig. 2. In general, convection aids in transmitting the power loss as heat to the coolant medium and does not cause any heat leakage as long as the box is perfectly airtight. Conduction is undesired in this case since it creates heat flux leakage paths through the box boundaries. Radiation contributes little to heat leakage. However, the use of aluminum sheets covering the inner surfaces of the box may promote heat exchange in a slightly favorable way. Heat loss by radiation is estimated to be negligible and appears in the linearity error of the calorimeter.

Overall, heat leakage primarily occurs at conductive connections, e.g., the walls, supporting legs, and machine shaft linkage. The heat leakage through the walls can be minimized by using high insulation materials and active wall temperature control [11]. Heat leakage through connection ports can be overcome by active port temperature control in parallel with further insulation arrangements [14]. 


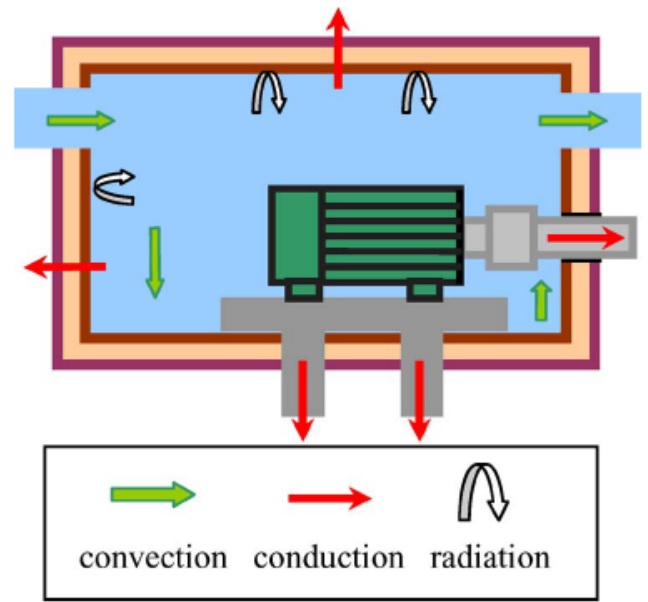

Fig. 2. Heat transfer in the calorimeter.

\section{Repeatability}

In addition to accuracy, repeatability is also a key performance indicator of any measuring instrument. It is self-evident to maintain a repeatable testing environment for calorimetric tests to be successful. In absolute terms, repeatability involves dismantling and reassembling the calorimeter, putting the same motor back into the calorimeter, and repeating the same test. This not only measures the calorimeter repeatability but also that of the supply system, of the loading system, and of the test motor loss. The problem is, therefore, split into parts.

Repeatable supply and load systems can reasonably be realized, but repeatability of the power delivered by the test machine itself is not guaranteed. Oil seals, the grease content in the bearings, and the changes between tests to the residual thrust between the two ball bearings that are commonly used to support the rotors of small commercial machines all give rise to variation of friction loss.

The ability to identify the power loss in the calorimeter is largely dictated by the measurement noise. Although averaging over long time periods can minimize the noise level on the measurement, it would also lose instant information during a test and would not remove the long-term drifts arising from variations of ambient temperature, humidity, and pressure.

\section{Design Considerations}

The 30-kW calorimeter is designed to have a maximum temperature rise of $20{ }^{\circ} \mathrm{C}$ at a constant mass flow rate of $0.2 \mathrm{~kg} / \mathrm{s}$ of dry air. The purpose of fixing the mass flow rate is to ensure that the temperature rise between inlet and outlet is independent of the air's pressure and humidity. This capacity corresponds to a maximum power loss of $4.5 \mathrm{~kW}$, representing the power loss in a $30-\mathrm{kW}$ motor with the lowest efficiency of $85 \%$. The calorimeter has internal dimensions of $1.3 \mathrm{~m} \times$ $0.8 \mathrm{~m} \times 0.8 \mathrm{~m}(\mathrm{~L} \times \mathrm{W} \times \mathrm{H})$, which are suitable for machine frame sizes of up to motor $250 \mathrm{~S}$. The loading system works best for machines rated at between 0.75 and $30 \mathrm{~kW}$.

The calorimeter has a low thermal conductivity across the walls. A sandwich form of 100 -mm-thick expanded polystyrene between two layers of 6-mm-thick aluminum sheet is employed

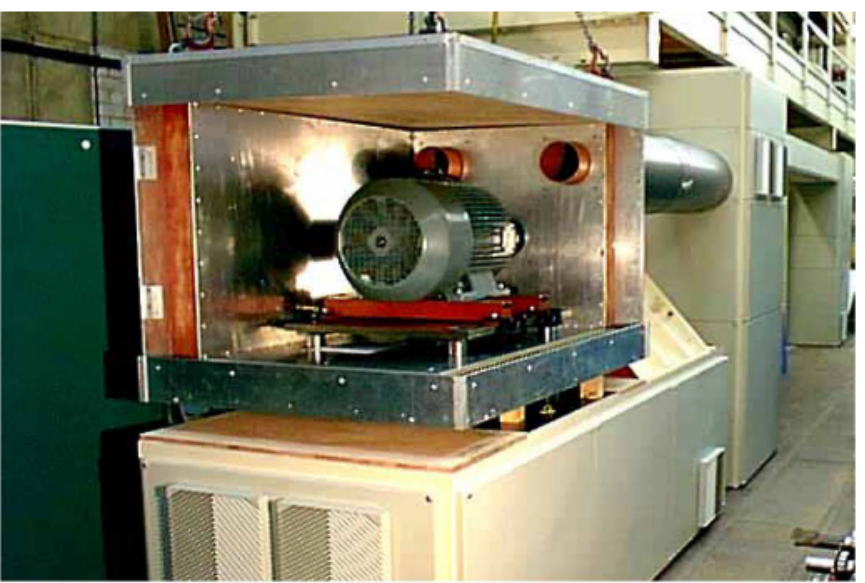

(a)

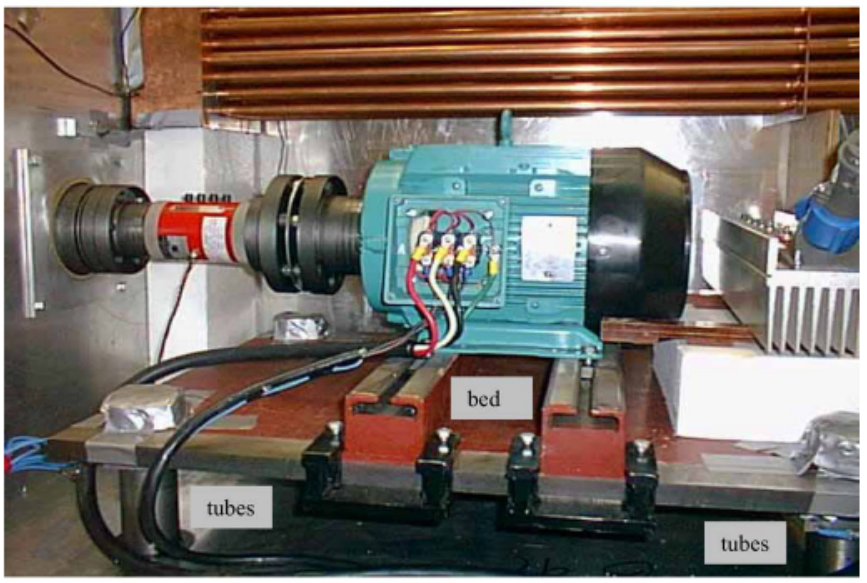

(b)

Fig. 3. Experimental setup of the calorimeter. (a) External view (end and side walls removed). (b) Internal view.

in the structure. Polystyrene is a reliable and cheap material for thermal insulation. Aluminum can conveniently be cut, shaped, and welded. It also has a high mechanical strength and thermal conductivity. The use of aluminum sheets covering all the surfaces inside and outside of the enclosure helps to achieve an isothermal condition on the walls. An additional advantage of selecting polystyrene and aluminum to construct the enclosure is their light weight, which potentially reduces the thermal time constant of the calorimeter.

Fig. 3 shows the experimental setup, and Fig. 4 illustrates the schematic of the whole calorimetric system. Air is initially cooled and then fed to a chamber containing the main circulation fan. This feeds through the main heater to a plenum chamber supplying a 4-m-long, 100-mm-diameter tube containing the high-pressure drop, multiple pipe flow straighteners, and volume-measuring turbine flowmeter. After flow measurement, a second plenum chamber collects the air that is then fed through a fine-tuned heater to the calorimeter.

The test machine is mounted on a steel bedplate supported by four 50 -mm-diameter, 2 -mm-thick steel tubes. The tubes are filled with insulation to prevent convection currents. Temperature sensors are installed in the tubes just inside and outside of the calorimeter. A heating arrangement using external heaters is designed to maintain no more than a $0.1^{\circ} \mathrm{C}$ temperature 


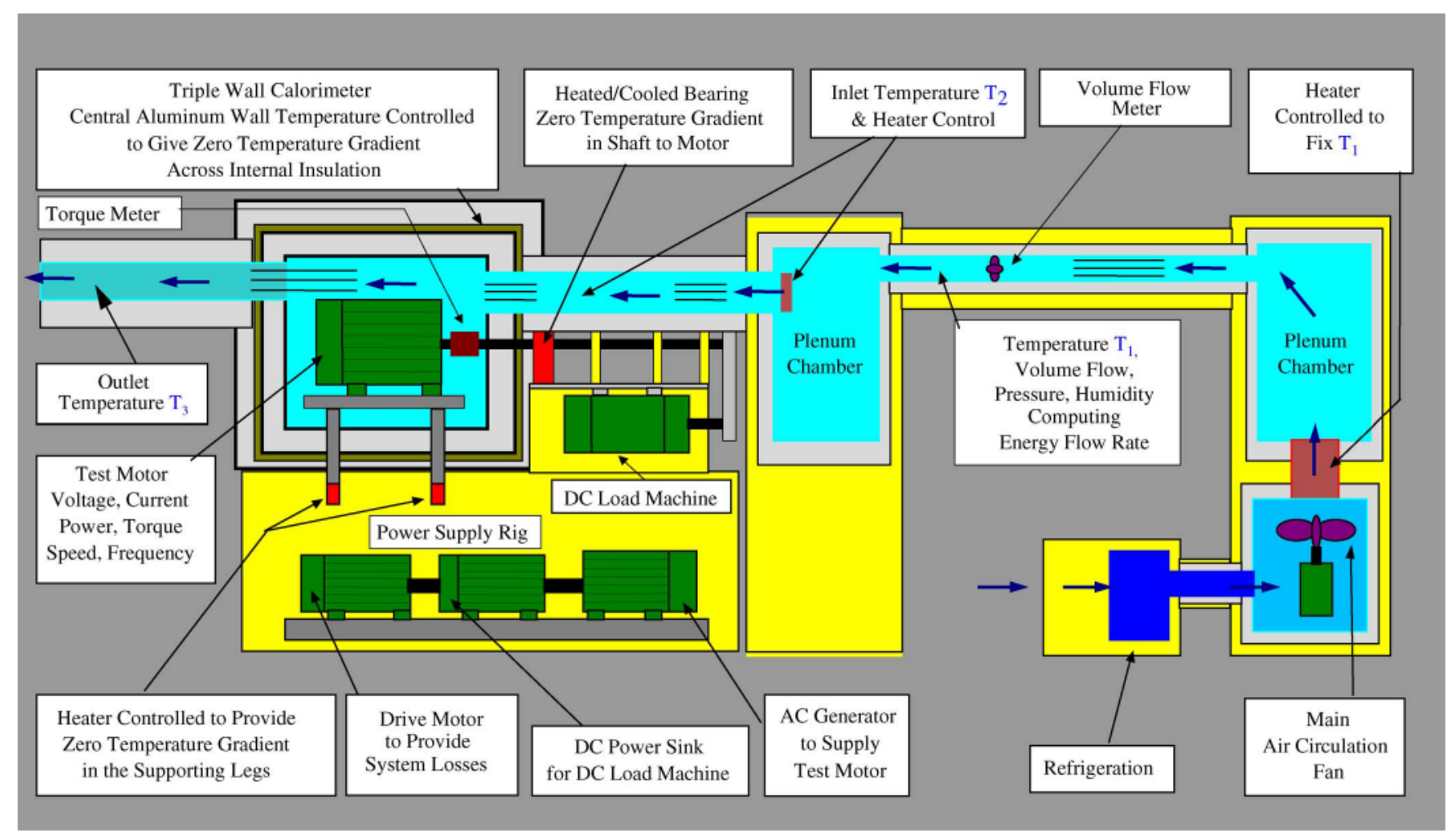

Fig. 4. Schematic of the $30-\mathrm{kW}$ calorimetric system.

gradient along the supporting legs inside and outside. The drive shaft is totally enclosed, and the bearing outside the calorimeter is insulated from the calorimeter wall. Similarly, it is oil cooled/heated to keep the temperature gradient in the shaft exit to be within $0.1^{\circ} \mathrm{C}$.

The outer walls of the calorimeter are fitted with a further layer of insulation and temperature-controlled heaters to ensure as close as possible an isothermal condition. The latter is achieved by a simple "bang-bang"--type control with $\pm 0.1{ }^{\circ} \mathrm{C}$ hysteresis. The temperature over the heated wall is not uniform, differing by as much as $0.5^{\circ} \mathrm{C}$ from the mean, but a weighted integration of the temperature with respect to area over each wall gives a mean temperature difference of approximately $0.1{ }^{\circ} \mathrm{C}$. The outer insulation reduces the power required by the heaters and, therefore, the temperature gradients in the interinsulation walls.

The thermal time constant of the calorimeter is estimated to be $40 \mathrm{~min}$. If the power loss is to be measured to an accuracy of $0.2 \%$, the operational time for a single test point should be at least 6.2 times the thermal time constant, which is approximately $4 \mathrm{~h}$. When a machine is installed inside the calorimeter for testing, the thermal constant will be altered and the test duration will be elongated, depending on the machine size.

\section{SySTEM CONTROL}

Energy flow control and power calculation are realized on a control computer via a LabView interface. A screen shot of the control program is given in Fig. 5. The sensors situated in the entry port of the calorimeter box measure the air's humidity, pressure, temperature, and volumetric flow rate and send these to the control computer via RS 232 and IEEE 488 interfaces. The LabView Virtual Instrument is employed to control a 14-bit data acquisition card (DAC) feeding the field controller of a dc generator, which is driven by an induction motor. PID control is implemented with digital filtering to enable the input power to the calorimeter to be defined in the increment of $1 \mathrm{~W}$. Voltage attenuators and current shunts are calibrated to $0.01 \%$ and $0.02 \%$, respectively.

For a calorimetric system to work best, it is critical to maintain a steady and repeatable testing environment over the long test period. This condition includes stable inlet and ambient temperatures, effective mass flow rate, supply and loading systems, and measurement instrumentation.

\section{A. Inlet Air Temperature}

The inlet air temperature is controlled through two heaters. The air coolant is initially cooled down to around $12{ }^{\circ} \mathrm{C}$ using two refrigeration units and subsequently heated up to approximately $14.5^{\circ} \mathrm{C}$ using a main heater (crude) in the first chamber. Prior to flowing into the calorimeter box, the coolant is further heated up to $15{ }^{\circ} \mathrm{C}$ using a fine-tuned heater in the second chamber. The coolant temperature at the point of measurement is controlled to be constant within $0.01^{\circ} \mathrm{C}$ of the set temperature point $\left(15^{\circ} \mathrm{C}\right)$.

\section{B. Air Flow Rate}

The air intake fan used to maintain the air flow through the calorimeter box is driven by a three-phase induction machine fed by an inverter. The air volumetric flow rate is dynamically 


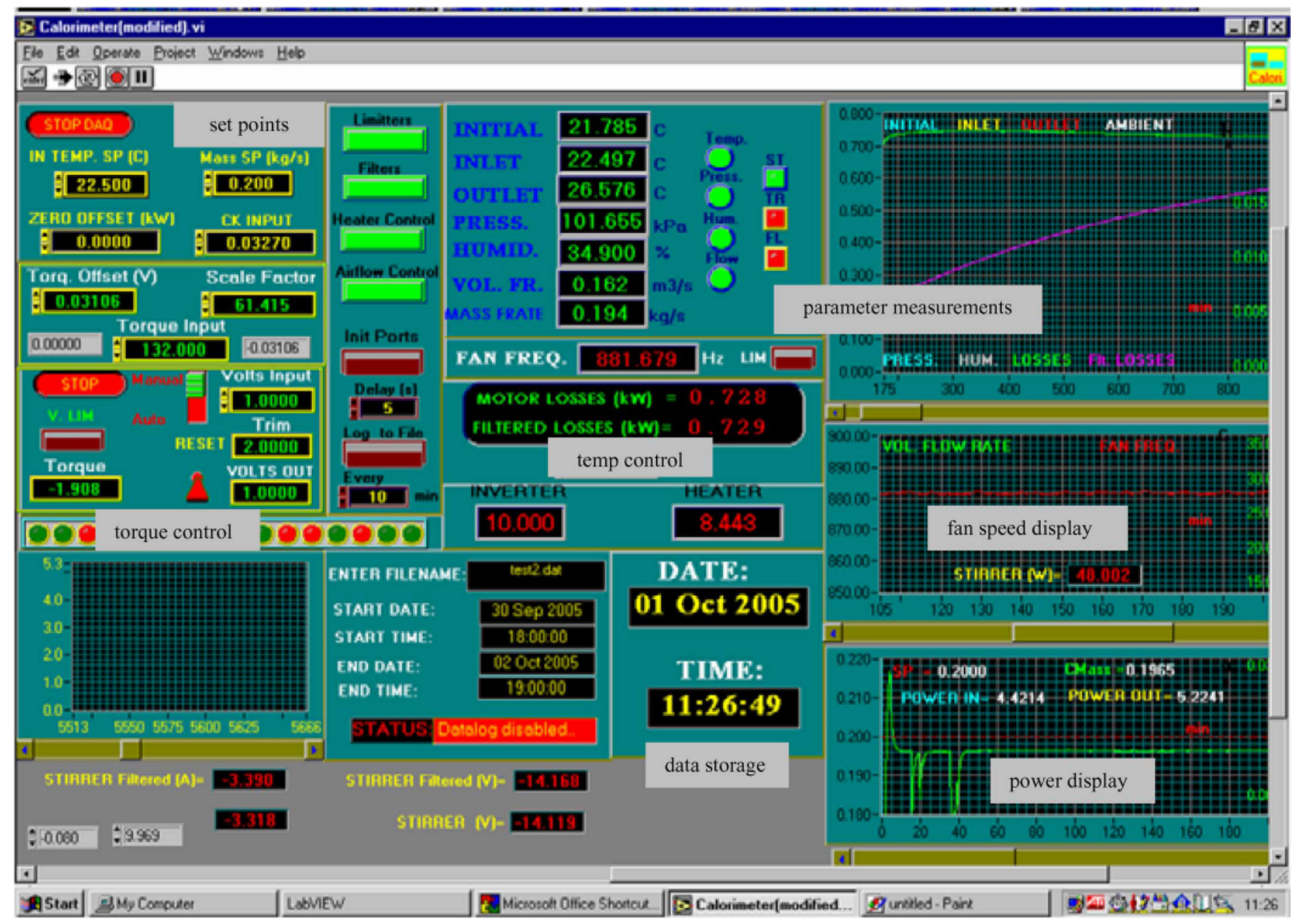

Fig. 5. Control interface in LabView.

controlled on the control computer to a fixed effective mass flow rate taking account of the atmospheric change. It is measured by a turbine flowmeter with a linearity of better than $1 \%$ and a specified repeatability of better than $0.05 \%$ within its calibration range. After careful calibration, the accuracy of the flowmeter will approximately be $0.05 \%$ of the full scale.

\section{Supply System}

Previous research [9], [14] has suggested that the incoming $50-\mathrm{Hz}$ mains is unable to provide reliable supply for test machines subject to accuracy measurement. The supply frequency, voltage magnitude, harmonic distortion, and phase imbalance all vary with time. Thereby, a separate supply system is developed to feed the test machines. The supply is produced by a generator that is mechanically connected to the dc load machine forming the Ward-Leonard configuration [2]. This supply is capable of providing a sinusoidal balanced threephase voltage waveform of low and unchanging distortion at a constant frequency of $\pm 0.01 \mathrm{~Hz}$ and a constant voltage of $\pm 0.1 \mathrm{~V}$ of the respective setpoint.

\section{Loading System}

The test machine is loaded by a dc machine that delivers its energy into an alternator and then supplies the test machine.
Active load control using an in-line torque transducer, chopperstabilized transducer amplifier, and computer-controlled data acquisition provides load variation that is controlled to be within $0.05 \%$ of the full range. A range of torque transducers is employed to maximize the loading performance for each particular test machine and to enhance the accuracy of torque measurement.

\section{E. Instrumentation}

Instrumentation includes proprietary instruments that are connected to the computer for control purposes. Two PT 100 temperature sensors are used to measure inlet and outlet air temperatures. Since PT 100 sensors have a stable resistance-temperature characteristic over a wide temperature range, they can offer excellent accuracy in temperature measurement. Even so, four-wire compensation circuits are used in this paper to overcome the offset error introduced by the lead resistance. The two sensors are calibrated together at the same time in a purpose-built computer-controlled calibration rig. This consists of a temperature-controlled cylindrical copper block supported in 100-mm thick insulation. Although absolute errors in temperature may be on the order of $0.02{ }^{\circ} \mathrm{C}$, the differential error is less than $0.01{ }^{\circ} \mathrm{C}$. The air temperature is calibrated to $0.01{ }^{\circ} \mathrm{C}$ with a resolution of $0.001{ }^{\circ} \mathrm{C}$. 
This applies to a particular air flow rate with a temperature equalizer installed in the duct to obtain a mean bulk air temperature.

Pressure can be measured to an accuracy of $0.013 \mathrm{kPa}$ with a resolution of $0.001 \mathrm{kPa}$, and humidity can be measured to an accuracy of $3 \%$ with a resolution of $0.1 \%$.

\section{F. Repeatability}

Repeatability when dismantling and reassembling the calorimeter is tested using the dc-supplied calibration heater, which is an accurate and reliable source of power loss. The error is no more than $2 \mathrm{~W}$ between tests within a $2-\mathrm{kW}$ level. For all the machines under test, repeatability is found to be typically within $12 \mathrm{~W}$ after correcting for small variations of input power. The supply system could be adjusted to give a repeatability of input power $(0.5 \%)$, line current $(0.5 \%)$, and voltage $(0.5 \%)$. The noise on the indicated power loss is less than $2 \mathrm{~W}$ for maximum machine rating. This can be reduced to below $0.1 \mathrm{~W}$ when averaging the indicated power loss over $3 \mathrm{~h}$ after steady state is attained.

\section{Results AND Discussions}

Experimental results are obtained from a complete set of calibration and standard tests on two induction motors rated at 5.5 and $30 \mathrm{~kW}$.

\section{A. Calibration}

The calibration of the calorimeter checks the precision of the whole system and also detects any shift or error over a certain period of time. Calibration points for the calorimeter are obtained using a heater fed with dc and a specially built power control rig. This dc heater is supplied by a half-controlled single-phase rectifier unit that is controlled to keep the power constant to within $1 \mathrm{~W}$ of the set power point. The current and voltage are measured by two Hall effect transducers so that the power to the heater can be measured to an accuracy of $0.5 \mathrm{~W}$.

The calorimeter is calibrated over power loss points of 10 , $500,1000,1500,2000$, and $2500 \mathrm{~W}$ and checked with the operating temperature between $20^{\circ} \mathrm{C}$ and $40^{\circ} \mathrm{C}$. At each known power to the heater, the calorimeter achieves its thermal balance and indicates a power value. Through fine control of the power to the heater, a set of measured points is obtained to yield a calibration curve. Any subsequent power loss calculation for machine testing is based on curve linearization. Test results from both heater and calorimeter are presented in Table I. It is clearly shown in this table that this calorimeter has good repeatability and linearity.

The overall linearity error is $0.5 \mathrm{~W}$, and the resolution is $0.1 \mathrm{~W}$. With the test machine replacing the heater, the overall accuracy is measured to be approximately $5.6 \mathrm{~W}$ on an extended range of $4.5 \mathrm{~kW}$. This error comprises 1-W calibration uncertainty, $0.5-\mathrm{W}$ linearity error, $2-\mathrm{W}$ repeatability, $2-\mathrm{W}$ calculation error in air properties, and $0.1-\mathrm{W}$ measurement noise.

The overall performance of the calorimetric system is summarized in Table II.
TABLE I

CALIBRATION RESUlts

\begin{tabular}{c|c}
\hline $\begin{array}{c}\text { Controlled input } \\
\text { power in W }\end{array}$ & $\begin{array}{c}\text { Calorimeter indicated } \\
\text { power in W }\end{array}$ \\
\hline 10 & 9.5 \\
\hline 500 & 500 \\
\hline 1000 & 1000 \\
\hline 1500 & 1500 \\
\hline 1997.5 & 1997 \\
\hline 2494.5 & 2494 \\
\hline
\end{tabular}

TABLE II

PERFormance Summary

\begin{tabular}{|c|c|c|c|c|}
\hline \multicolumn{2}{|c|}{ Item } & Accuracy & Resolution & Repeatability \\
\hline \multicolumn{2}{|c|}{ Overall system } & $\begin{array}{c}5.6 \mathrm{~W} \text { for } 4.5 \\
\mathrm{~kW} \text { power loss }\end{array}$ & $0.1 \mathrm{~W}$ & $2 \mathrm{~W}$ \\
\hline \multirow{4}{*}{ Control } & air temperature & $0.01^{\circ} \mathrm{C}$ & $0.001^{\circ} \mathrm{C}$ & \\
\hline & $\begin{array}{l}\text { active temperature } \\
\text { at boundaries }\end{array}$ & $0.1^{\circ} \mathrm{C}$ & & \\
\hline & calibration power & $1 \mathrm{~W}$ & $0.1 \mathrm{~W}$ & $0.1 \mathrm{~W}$ \\
\hline & loading & $0.05 \%$ & & \\
\hline \multirow{4}{*}{ Supply } & power & & & $0.5 \%$ \\
\hline & frequency & $0.01 \mathrm{~Hz}$ & $0.01 \mathrm{~Hz}$ & \\
\hline & voltage & $0.1 \mathrm{~V}$ & & $0.5 \%$ \\
\hline & current & & & $0.5 \%$ \\
\hline \multirow{11}{*}{ Measurement } & volume flow rate & $0.05 \%$ & & $0.05 \%$ \\
\hline & air temperature & $0.01^{\circ} \mathrm{C}$ & $0.001^{\circ} \mathrm{C}$ & \\
\hline & humidity & $3 \%$ & $0.1 \%$ & \\
\hline & pressure & $0.013 \mathrm{kPa}$ & $0.001 \mathrm{kPa}$ & \\
\hline & frequency & $0.02 \%$ & & \\
\hline & power & $0.1 \%$ & & \\
\hline & voltage & $0.01 \%$ & & \\
\hline & current & $0.02 \%$ & & \\
\hline & resistance & $0.02 \%$ & & \\
\hline & speed & $1 \mathrm{rpm}$ & $0.1 \mathrm{rpm}$ & \\
\hline & torque & $0.1 \%$ & & \\
\hline
\end{tabular}

\section{B. Machine Testing}

Two induction motors are carefully tested in the calorimeter and on another test rig outside of the calorimeter. Since the stray load loss in a machine is a sensitive component derived from subtracting the identifiable losses from the total loss, it is employed in this paper for comparison between calorimetric and input-output methods in detecting a small loss change. Loss segregation complies with IEEE 112 method B. The test results are plotted in Figs. 6 and 7 for comparison.

Fig. 6 shows a four-pole, $50-\mathrm{Hz}, 5.5-\mathrm{kW}$ induction motor, and Fig. 7 shows a four-pole, $50-\mathrm{Hz}, 30-\mathrm{kW}$ motor. A range of load values including $25 \%, 50 \%, 75 \%, 90 \%$, and $100 \%$ is obtained by the calorimeter along with one or two sets of IEEE 112-B test results, which further extends load points.

Clearly, the two figures show a good agreement on the stray load loss between calorimetric and IEEE 112-B methods. The latter is proven to be an accurate method among existing standards for testing induction motors [19]. From both figures, it can also be seen that the calorimetric results present a linear curve shape going through the zero load points, whereas the IEEE 112-B results give a small degree of curvature and zero offset. Nevertheless, the slope of the IEEE 112-B curves fitted by regression analysis is very close to that of calorimetric results. According to the standard, the stray load loss is then 


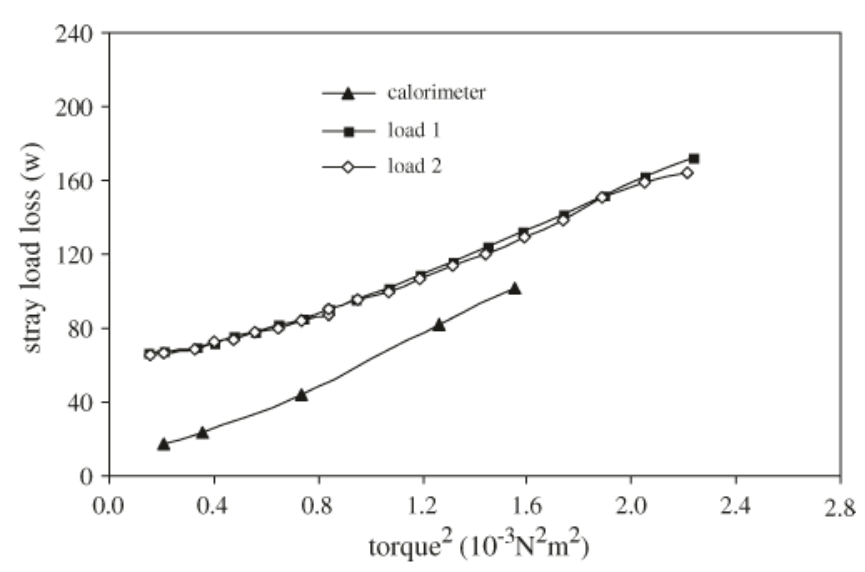

Fig. 6. Stray load loss results for the $5.5-\mathrm{kW}$ motor.

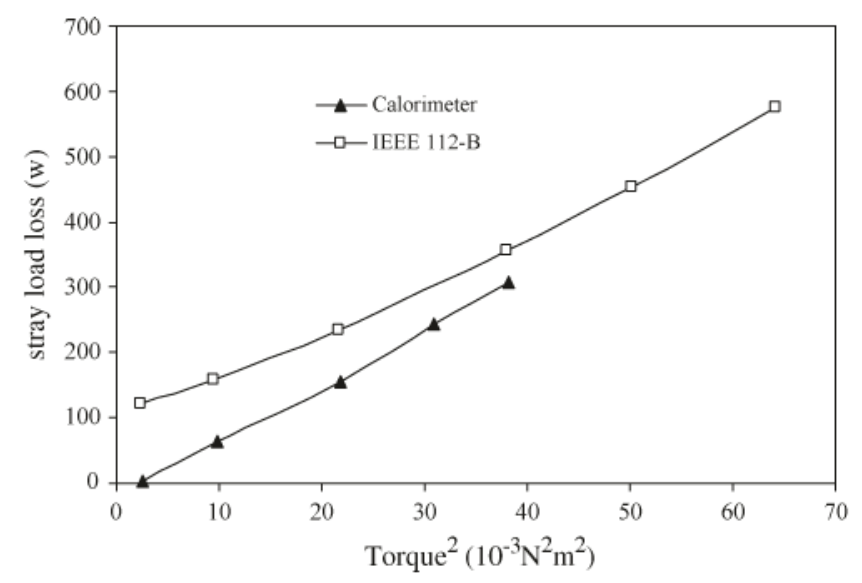

Fig. 7. Stray load loss results for the $30-\mathrm{kW}$ motor.

corrected to fit to a specific machine model by removing the constant offset and applying linearization for stray load loss. All the correction factors exceed 0.95 , and constant zero offsets are within the accuracy that the instrumentation could achieve.

Obviously, these test results justify the development of this calorimeter in terms of detecting a very small loss in the electrical machine. The comparison of calorimetric and IEEE 112-B methods further confirms the effectiveness of the calorimetric approach.

\section{CONCLUSION}

This paper has described the development of a high-precision air-cooled calorimeter capable of measuring power loss in electrical machines rated at up to $30 \mathrm{~kW}(40 \mathrm{hp})$. The accuracy is approximately $5.6 \mathrm{~W}$ for the full power range of $4.5 \mathrm{~kW}$, while the calorimeter is initially calibrated to $2.5 \mathrm{~kW}$. During the design and implementation of the calorimetric system, much attention has been paid to the accurate measurement of the air's thermal properties, the prevention of heat leakage, and the maintenance of steady and repeatable testing conditions. Careful design of calorimeter structure and the use of active temperature control ensure that a thermally insulated enclosure can be achieved with minimized heat loss. The design of inlet and outlet ducts and the use of high-precision instrumentation significantly reduce the errors in temperature measurement. Control strategies using LabView software enable the control of effective mass flow rate to be constant over a long period of time. Experimental results from calibration and standard machine tests clearly confirm the calorimeter's capacity of detecting a very small power loss to a very high degree of accuracy. Owing to its high precision, this calorimeter has potential for the investigation of stray load and harmonic losses, thus enabling higher efficiency machines and power electronic devices to be developed, refined, and validated.

\section{ACKNOWLEDGMENT}

The authors would like to thank the contribution of Prof. G. M. Asher on the preparation of this paper.

\section{REFERENCES}

[1] B. J. Chalmers and A. C. Williamson, "Stray losses in squirrel-cage induction motors," Proc. Inst. Elect. Eng., vol. 110, pp. 1773-1778, 1963.

[2] W. Cao, K. J. Bradley, and J. Allen, "Evaluation of additional loss in induction motors consequent upon repair and rewinding," Proc. Inst. Elect. Eng.-Elect. Power Appl., vol. 153, no. 1, pp. 1-6, Jan. 2006.

[3] S. J. Salon, L. Ovacik, and J. F. Bailey, "Finite element calculation of harmonic losses in AC machine windings," in Dig. 5th Biennial IEEE Conf. Electromagn. Field Comput., Aug. 3-5, 1992, p. TP25.

[4] K. Yamazaki and Y. Haruishi, "Stray load loss analysis of induction motor-comparison of measurement due to IEEE Standard 112 and direct calculation by finite-element method," IEEE Trans. Ind. Appl., vol. 40, no. 2, pp. 543-549, Mar./Apr. 2004.

[5] IEEE Standard Test Procedure for Polyphase Induction Motors and Generators (ANSI), IEEE Std. 112-1996 (IEEE 112-1991), May 1, 1996.

[6] General Requirements for Rotating Electrical Machines-Part 102: Methods for Determining Losses and Efficiency From Tests (Excluding Machines for Traction Vehicles), IEC 34-2: 1972 (IEC 34-2A 1974) (BS EN 60034-2), Jan. 1, 1972.

[7] R. Linkous, A. W. Kelley, and K. C. Armstrong, "An improved calorimeter for measuring the core loss of magnetic materials," in Proc. 15th Annu. IEEE APEC, 2000 , vol. 2, pp. 633-639.

[8] D. Jacob, "Determination of the losses of a PWM converter fed induction motor-An original loss summation method," in Proc. ICEM, 1990, vol. 2, pp. 319-325.

[9] D. R. Turner, K. J. Binns, B. N. Shamsadeen, and D. F. Warne, "Accurate measurement of induction motor losses using balance calorimeter," Proc. Inst. Elect. Eng.-Elect. Power Appl., vol. 138, no. 5, pp. 233-242, Sep. 1991.

[10] Y. Suzuki, N. Chida, A. Murata, and T. Inoue, "A calorimeter for optical fiber power standard and advantages in calibration of optical fiber power meters," IEEE Trans. Instrum. Meas., vol. 42, no. 2, pp. 430-433, Apr. 1993.

[11] B. Baholo, P. H. Mellor, D. Howe, and T. S. Birch, "An automated calorimetric method of loss measurement in electrical machines," J. Magn. Magn. Mater., vol. 133, no. 1-3, pp. 433-436, 1994.

[12] O. Aglen, "Calorimetric measurement of losses in air cooled and water cooled asynchronous motors," in Proc. ICEM, Vigo, Spain, vol. 3, pp. 256-262.

[13] P. D. Malliband, D. R. H. Carter, B. M. Gordon, and R. A. McMahon, "Design of a double-jacketed, closed type calorimeter for direct measurement of motor losses," in Proc. 7th Int. Conf. Power Electron. Variable Speed Drives, Sep. 21-23, 1998, pp. 212-217.

[14] P. McLeod, K. J. Bradley, A. Ferrah, R. Magill, J. C. Clare, P. Wheeler, and P. Sewell, "High precision calorimetry for the measurement of the efficiency of induction motors," in Conf. Rec. 33rd IEEE IAS Annu. Meeting, Oct. 12-15, 1998, vol. 1, pp. 304-311.

[15] A. Jalilian, V. J. Gosbell, B. S. P. Perera, and P. Cooper, "Double chamber calorimeter (DCC): A new approach to measure induction motor harmonic losses," IEEE Trans. Energy Convers., vol. 14, no. 3, pp. 680-685, Sep. 1999.

[16] B. Szabados and A. Mihalcea, "Design and implementation of a calorimetric measurement facility for determining losses in electrical machines," IEEE Trans. Instrum. Meas., vol. 51, no. 5, pp. 902-907, Oct. 2002. 
[17] P. D. Malliband, N. P. van der Dujin Schouten, and R. A. McMahon, "Precision calorimetry for the accurate measurement of inverter losses," in Proc. Int. Conf. PEDS, Singapore, Nov. 2003, pp. 321-326.

[18] E. Ritchie, J. K. Pedersen, F. Blaabjerg, and P. Hansen, "Calorimetric measuring systems," IEEE Ind. Appl. Mag., vol. 10, no. 3, pp. 70-78, May/Jun. 2004.

[19] K. J. Bradley, W. Cao, and J. Arellano-Padilla, "Evaluation of stray load loss in induction motors with a comparison of input-output and calorimetric methods," IEEE Trans. Energy Convers., vol. 21, no. 3, pp. 682-689, Sep. 2006.

[20] W. Cao, K. J. Bradley, I. French, and H. Zhang, "A review of calorimetric application for accurate power loss measurement," in Proc. 41st Int. UPEC, Newcastle, U.K., Sep. 6-8, 2006, pp. 550-554.

[21] K. J. Bradley, A. Ferrah, R. Magill, J. C. Clare, P. Wheeler, and P. Sewell, "Improvements to precision measurement of stray load loss by calorimeter," in Proc. 9th Int. Conf. Elect. Mach. Drives, 1999, pp. 189-193.

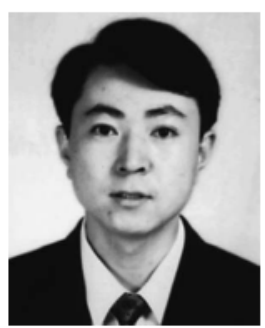

Wenping Cao (M'05) received the Ph.D. degree in electrical machines and drives from the University of Nottingham, Nottingham, U.K., in 2004.

Between January 2004 and January 2005, he was an Electrical Engineering Technologist with the University of Sheffield, Sheffield, U.K. Between January 2005 and February 2006. he was a Research Fellow with the University of Nottingham. He is currently a Senior Lecturer with the University of Teesside, Middlesbrough, U.K. His current research interests are energy-efficiency improvements in the design, operation, and repair of electric machines and drives.

Dr. Cao is a member of the Institution of Engineering and Technology.

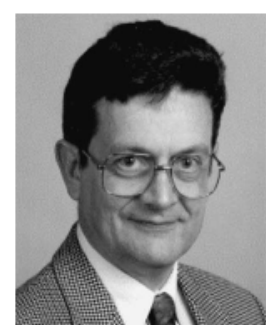

Keith J. Bradley (A'93) received the Ph.D. degree in shaded pole motors from the University of Sheffield, Sheffield, U.K., in 1974.

Following a period of research in low-vibration induction motors for nuclear submarines with YARD Ltd., he joined the School of Electrical and Electronic Engineering, University of Nottingham, Nottingham, U.K. His current research interests are concerned with tailoring machine design to optimize variable-speed drive performance and efficiency.

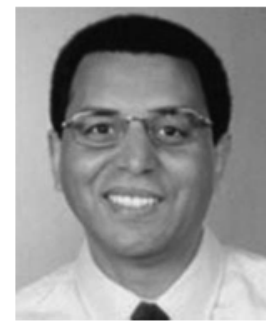

Azzeddine Ferrah (M'96) received the Engineer of State degree from the University of Sciences and Technology, Oran, Algeria, the M.Phil. degree from Swansea University, Swansea, U.K., in 1989, and the Ph.D. degree from Nottingham University, Nottingham, U.K., in 1993.

$\mathrm{He}$ is currently with Sohar University, Sohar, Oman. His research interests are electrical machines, drives, and the application of signal processing to drives. 